\title{
EFEKTIVITAS PROGRAM KAWASAN RUMAH PANGAN LESTARI (KRPL) DI DESA AWAR-AWAR KECAMATAN ASEMBAGUS
}

\author{
Abdi Kuspriyantono \\ Balai Penyuluhan Pertanian \\ Dinas Tanaman Pangan, Holtikulutura dan Perkebunan Situbondo \\ Email Korespondensi : kuspriyantonoabdi@gmail.com
}

\begin{abstract}
Abstrak
Tujuan penelitian ini adalah untuk menganalis efektivitas Program KRPL (Kawasan Rumah Pangan Lestari), faktor-faktor yang mempengaruhi implementasi program KRPL, dan efesiensi program KRPL. Penelitian ini dilaksanakan di Desa Awar-Awar Kecamatan Asembagus Kabupaten Situbondo. Metode pengumpulan data menggunakan wawancara langsung dan dokumentasi. Data yang diperoleh dianalisis secara deskriptif dan menggunakan analisa statistik regresi linier berganda dan diuji menggunakan uji T dan uji F. Hasil penelitian menunjukkan bahwa (1) efektivitas Program KRPL di desa Awar-Awar Kecamatan Asembagus sebesar 40\% dan termasuk dalam kategori tidak efektif, (2) berdasarkan uji $\mathrm{F}$, secara simultan variabel X mempengaruhi implementasi program KRPL (Y), (3) berdasarkan uji T, secara parsial hanya variabel pendidikan (X3) dan hobby (X5) yang mempengaruhi faktor implementasi KRPL (Y), dan (4) program KRPL di desa AwarAwar Kecamatan Asembagus tidak efisien.
\end{abstract}

Kata kunci: KRPL, efektivitas, faktor penentu implementasi, efisiensi

\begin{abstract}
The purpose of this study is to analyze the effectiveness of the KRPL Program (Sustainable Food Houses Area), the factors that influence the implementation of the KRPL program, and the efficiency of the KRPL program. This research was conducted in Awar Awar Village, Asembagus District, Situbondo Regency. The data collection method uses direct interviews and documentation. The data obtained were analyzed descriptively and using statistical analysis of multiple linear regression and tested using the $T$ test and $F$ test. The results showed that (1) the effectiveness of the KRPL Program in the Awar-Awar village of Asembagus District was 40\% and included in the ineffective category, (2) based on the F test, simultaneously variable $X$ affects the KRPL program implementation (Y), (3) based on the T test, partially only educational variables (X3) and hobbies (X5) affect the KRPL implementation factor ( $Y$ ), and (4) KRPL program in Awar-Awar village, Asembagus District is inefficient.
\end{abstract}

Keywords: KRPL program, effectiveness, influential facors of implementation, efficiency

\section{PENDAHULUAN}

Pertambahan penduduk dan alih fungsi lahan merupakan dua hal yang tidak dapat dipisahkan dan dihindarkan. Semakin tinggi jumlah pertumbuhan penduduk, akan berakibat pada alih fungsi lahan yang semakin tinggi pula. Peningkatan jumlah penduduk berbanding lurus dengan peningkatan konsumsi dan meningkatnya urbanisasi penduduk dari desa ke kota yang dipenuhi dari luar kota. Artinya pangan kedepan menjadi sangat strategis (tanaman bahan pangan akan diperebutkan negara- negara besar). Kondisi saat ini masih ketergantungan konsumsi pada satu bahan pangan pokok yaitu beras, dimana beras sebagai bahan pangan utama yang cenderung terus meningkat setiap tahunnya seiring dengan peningkatan jumlah penduduk. Sehingga nampak jelas bahwa kemandirian pangan bangsa ini masih jauh panggang dari api. 
Kemandirian pangan yang dicirikan dengan tersedianya pangan yang bergizi dan aman untuk kesehatan dalam jumlah yang cukup sepanjang waktu merupakan keniscayaan yang tidak terbantahkan, sehingga pemerintah dan masyarakat harus terus bekerjasama secara kreatif dan kritis dalam mewujudkan dan kemudian mempertahankannya.

Adanya kesadaran atas perlunya kerjasama yang kreatif dan kritis antara pemerintah dan masyarakat untuk mewujudkan kemandirian pangan tersebutlah maka mulai tahun 2012, Kementerian Pertanian melalui Badan Litbang Pertanian bekerjasama dengan masyarakat di beberapa daerah di Indonesia menginisiasi suatu program pemanfaatan pekarangan dan lahan sempit sebagai tempat produksi bahan pangan yang dibutuhkan oleh keluarga Indonesia.

Program tersebut diberi nama Program Kawasan Rumah Pangan Lestari (KRPL), dimana dikreasi dari salah satu budaya bangsa yang berharga yaitu memanfaatkan pekarangan sebagai sumber bahan pangan keluarga melalui penanaman berbagai tanaman sayuran, buah-buahan, umbi-umbian dan tanaman obat serta pemeliharaan ternak dan ikan (Kementerian Pertanian. 2011).

Menurut Softi Nur Rahmah, Helfia Edial, Yuherman (2013), bahwa Kawasan Rumah Pangan Lestari (KRPL) merupakan salah satu program Kementerian Pertanian dalam rangka optimalisasi lahan pekarangan yang ramah lingkungan dalam suatu kawasan. Keberlanjutan dalam pemanfaatan lahan pekarangan dalam kegiatan Kawasan Rumah Pangan Lestari (KRPL), tentunya banyak faktor-faktor yang mempengaruhi dalam pengembangan pemanfaatan lahan pekarangan, faktor-faktor tersebut antara lain: a.) Tingkat Pendidikan, b.) Luas Lahan, c.) Waktu Luang.

Berdasarkan latar belakang di atas maka ditetapkan identifikasi masalah yaitu bagaimana efektivitas program kawasan rRumah pangan lestari (KRPL) Di Desa AwarAwar Kecamatan Asembagus, faktor-faktor apa yang mempengaruhi implementasi program KRPL dan bagaimana efisiensi program KRPL di Desa Awar-Awar.

\section{METODE PENELITIAN}

\section{Tempat dan Waktu Penelitian}

Penelitian dilakukan pada bulan bulan Januari s/d bulan Maret 2019. Pemilihan lokasi dilakukan secara purposive yaitu berdasarkan pada kriteria tertentu. Lokasi ini dipilih atas pertimbangan bahwa Desa Awar-Awar Kecamatan Asembagus Kabupaten Situbondo merupakan salah satu penerima program Kawasan Rumah Pangan Lestari (KRPL). Pelaksana kegiatan adalah Dasa Wisma Melati dan sampai sekarang masih berjalan.

\section{Populasi da Sampel}

Sugiyono (2013 Populasi adalah wilayah generalisasi terdiri atas obyek atau subyek yang mempunyai kualitas dan karakteristik tertentu. Dalam penelitian ini populasinya adalah semua pengurus dan anggota dasawisma melati sebanyak 20 orang. Sampel adalah sebagian dari jumlah dan karakteristik yang dimiliki oleh populasi tersebut. Sedangkan menurut Arikunto (2008), penentuan pengambilan sampel apabila kurang dari 100 lebih baik diambil semua sehingga penelitiannya merupakan penelitian populasi. Dalam penelitian ini teknik pengambilan sampel menggunakan metode Sensus, dimana seluruh populasi atau anggota dasawisma melati dijadikan sebagai subyek penelitian atau sampel. 


\section{Teknik Pengumpulan Data}

Berdasarkan jenis data yang dikumpulkan dalam penelitian ini dibedakan menjadi dua kelompok yaitu data primer dan data sekunder. Data primer merupakan data yang didapatkan melalui wawancara, pengukuran, dan pengamatan langsung di lapangan. Data sekunder adalah pengumpulan data yang dilakukan melalui studi kepustakaan yang terdiri dari mengumpulkan buku-buku, karya ilmiah, makalah yang memiliki relevansi dengan masalah efektivitas program kawasan rumah pangan lestari. berikut :

Teknik pengumpulan data dalam penelitian ini dilakukan dengan cara sebagai

1. Kuesioner adalah suatu cara pengumpulan data dengan cara memberikan daftar pertanyaan yang telah disediakan kepada responden yaitu pengurus dan anggota Dasawisma Melati.

2. Wawancara adalah proses memperoleh data dengan cara tanya jawab secara langsung dan temu muka langsung dengan pengurus dan anggota Dasawisma Melati. Pengumpulan data seperti ini dituntut untuk melakukan banyak pelacakan guna mendapatkan data yang lebih dalam, utuh, dan rinci.

\section{Metode Analisis Data}

Metode analisis data yang diterapkan selaras dengan metode penelitian yang digunakan yaitu deskriptif kuantitatif. Data yang diperoleh diolah dan disederhanakan dengan bantuan kalkulator dan komputer dengan menggunakan Microsoft Excel kemudian dianalisis menggunakan SPSS ver 15. Data primer dan sekunder yang diperoleh (umur, jenis kelamin, pendidikan, luas lahan, hobi dan pendampingan petugas terhadap implementasi program KRPL) ditabulasi terlebih dahulu ke dalam aplikasi Microsoft Excel, lalu dianalisis dengan menggunakan aplikasi SPSS ver 15 menggunakan regresi linier berganda untuk uji T partial dan uji F simultan. Analisis yang dilakukan adalah sebagai berikut :

1. Bagaimana Efektivitas Program Kawasan Rumah Pangan Lestari (KRPL) Di Desa Awar-Awar Kecamatan Asembagus.

Menurut Supriyono (2011) menyatakan efektivitas merupakan hubungan antara keluaran suatu pusat tanggung jawab dengan sasaran yang mesti dicapai, semakin besar kontribusi daripada keluaran yang dihasilkan terhadap nilai pencapaian sasaran tersebut, maka dapat dikatakan efektif pula unit tersebut.

Rumus :

$$
\text { Efektivitas }=\frac{\text { Realisasi }}{\text { Target }} \times 100 \%
$$

Sumber : Litbang Depdagri R.I No. 690.900.327.1991

2. Faktor -Faktor apa yang mempengaruhi implementasi program KRPL.

Metode analisis yang digunakan untuk mengetahui pengaruh karakteristik responden (umur, jenis kelamin, pendidikan, luas lahan, hobi dan pendampingan) terhadap implementasi program KRPL adalah analisis regresi linier berganda dengan alat analisis yang digunakan adalah SPSS 15 for windows. Menurut Sugiyono (2013), analisa regresi berganda digunakan oleh peneliti, bila peneliti bermaksud meramalkan bagaiman keadaan (naik - turunnya) variabel dependen, bila dua atau lebih variabel independen sebagai faktor prediktor dimanipulasi (dinaik turunkan nilainya). Dengan persamaan regresi linier berganda sebagai berikut : 


$$
Y=a+b_{1} X_{1}+b_{2} X_{2}+b_{3} X_{3}+b_{4} X_{4}+b_{5} X_{5}+b_{6} X_{6}
$$

3. Apakah program KRPL di Desa Awar-Awar efisien.

Untuk mengukur efisiensi menggunakan rumus Rasio R/C sebagai berikut

$$
\mathrm{R} / \mathrm{C} \text { Ratio }=\frac{\mathrm{TR}}{\mathrm{TC}}
$$

Dimana :

TR : Besarnya Total Penerimaan (Total Revenue)

TC : Besarnya Total Biaya Produksi (Total Cost)

Dengan ketentuan sebagai berikut :

Jika rasio $\mathrm{R} / \mathrm{C}>1$, maka program KRPL tergolong efisien dan menguntungkan.

Jika rasio $\mathrm{R} / \mathrm{C}=1$ maka program KRPL tergolong antara efisien dan tidak efisien.

Jika rasio $\mathrm{R} / \mathrm{C}<1$, maka program KRPL tergolong tidak efisien dan merugikan

\section{HASIL DAN PEMBAHASAN}

\section{Gambaran Umum Lokasi Penelitian}

Kecamatan Asembagus memiliki luas wilayah 118,74 $\mathrm{Km}^{2}$ atau 1187,4 Ha dengan ketinggian 0-25 mdpl. Curah hujan rata-rata $112 \mathrm{Mm} /$ tahun, dan jumlah hari dengan curah hujan terbanyak ialah 60 hari, dengan temperatur sekitar 19-25ㄷ. Kecamatan Asembagus memiliki bentuk wilayah hamparan dataran rendah.

Desa Awar-Awar merupakan salah satu desa di Kecamatan Asembagus, dengan jarak $0.5 \mathrm{Km}$ dari Kantor Kecamatan Asembagus, $25 \mathrm{Km}$ dari Ibukota Kabupaten Situbondo. memiliki luas areal wilayah sebesar 355 Ha dan berada pada ketinggian 0-25 mdpl diatas permukaan air laut. Merupakan dataran rendah dengan suhu rata-rata tahunan sekitar $28-32^{\circ} \mathrm{C}$.

\section{Efektivitas Program Kawasan Rumah Pangan Lestari (KRPL)}

Efektivitas merupakan salah satu syarat keberhasilan suatu program yang diimplementasikan oleh pemerintah. Efektivitas juga sebagai ukuran tingkat pemenuhan output atau tujuan proses. Semakin tinggi pencapaian target atau pencapaian proses maka dikatakan proses tersebut semkin efektif.

Indikator efektivitas diidentifikasi pada output atau pendapatan responden atas apa yang mereka upayakan pada program KRPL ini. Jika pendapatan mereka sesuai maka kepuasan responden juga akan baik sehingga mampu menggambarkan keberhasilan program tersebut. Efektivitas program KRPL di Desa Awar-awar dapat dilihat pada tabel dibawah ini :

Tabel 1. Efektivitas Program KRPL di Desa Awar-awar

\begin{tabular}{lc}
\hline Realisasi & 8 \\
Target & 20 \\
\hline Efektivitas program KRPL & $40 \%$ \\
\hline Sumber : data primer diolah &
\end{tabular}

Dari tabel diatas menunjukkan efektifitas KRPL sebesar 40\%. Hal ini menunjukkan bahwa efektifitas KRPL masih tergolong rendah karena dipengaruhi oleh pengaruh luas lahan dan minat yang kurang dalam bercocok tanam. Kemudian dari faktor eksternal 
kegiatan KRPL ini kurang dimonitoring oleh Dinas/Instansi terkait sehingga banyak anggota KRPL kurang fokus dalam setiap kegiatan baik pertemuan kelompok maupun kegiatan di lapangan/kebun. Sehingga lambat laun anggota tidak paham bagaimana pola pemeliharaan tanaman sayuran baik itu pada bedengan halaman rumah maupun pada sistem ventrikultur.

\section{Faktor-faktor yang mempengaruhi implementasi program KRPL}

Variabel independen (variabel $\mathrm{X}$ ) yang digunakan yaitu umur $\left(\mathrm{X}_{1}\right)$, jenis kelamin $\left(X_{2}\right)$, pendidikan $\left(X_{3}\right)$, luas lahan $\left(X_{4}\right)$, hobby $\left(X_{5}\right)$ dan pendampingan peetugas $\left(X_{6}\right)$. Sedangkan implementasi program KRPL (faktor $\mathrm{Y}$ ) didalamnya terdapat pengetahuan (Y1.1), manfaat (Y1.2) dan pemasaran (Y1.3).

Untuk mengetahui pengaruh variabel-variabel yang mempengaruhi implementasi program KRPL, digunakan analisa regresi linier berganda untuk masing-masing variabel independen sebagai berikut :

Tabel 2. Analisa Regresi Linier Berganda, Variabel Yang Mempengaruhi Implementasi Program KRPL (faktor Y).

\begin{tabular}{lccccc}
\hline \multicolumn{1}{c}{ variable } & Notasi & $\begin{array}{c}\text { Koefisien } \\
\text { regresi }\end{array}$ & T hitung & T tabel & Sig. \\
\hline Umur & $\mathrm{X}_{1}$ & 0,004 & 0,293 & & 0,774 \\
Jenis kelamin & $\mathrm{X}_{2}$ & $-0,328$ & $-1,244$ & & 0,235 \\
Pendidikan & $\mathrm{X}_{3}$ & 0,160 & 3,485 & 2,160 & 0,004 \\
Luas lahan & $\mathrm{X}_{4}$ & 0,007 & 1,902 & & 0,080 \\
Hobby & $\mathrm{X}_{5}$ & 1,204 & 4,007 & & 0,001 \\
Pendampingan PPL & $\mathrm{X}_{6}$ & 0,135 & 0,552 & & 0,590 \\
\hline Konstante & & & & & 0,126 \\
Koefisien Determinasi ${ }^{2}$ & & & & & 0,906 \\
F Hitung & & & & & 20,912 \\
F Tabel & & & &
\end{tabular}

Dari hasil analisa tersebut diatas maka dapat diketahui persamaan regresi linier berganda pada faktor-faktor yang mempengaruhi program KRPL sebagai berikut :

$$
\begin{aligned}
& Y=a+b_{1} X_{1}+b_{2} X_{2}+b_{3} X_{3}+b_{4} X_{4}+b_{5} X_{5}+b_{6} X_{6} \\
& \mathrm{Y}=\begin{array}{l}
0,126+0,004\left(\mathrm{X}_{1}\right)-0,328\left(\mathrm{X}_{2}\right)+0,160\left(\mathrm{X}_{3}\right)+0,007\left(\mathrm{X}_{4}\right)+1,204\left(\mathrm{X}_{5}\right)+ \\
0,135\left(\mathrm{X}_{6}\right)
\end{array}
\end{aligned}
$$

Berdasarkan rumus regresi di atas menunjukkan hal-hal sebagai berikut:

1. Konstanta (a) $=0,126$

Nilai konstanta 0,126 menunjukkan apabila variabel umur, jenis kelamin, pendidikan, luas lahan, hobby dan pendampingan PPL konstan, maka implementasi KRPL sebesar 12,6 \%.

2. Umur $\left(\mathrm{X}_{1}\right)=0,004$

Umur anggota tidak mempengaruhi program KRPL dengan nilai koefisien sebesar 0,004. Artinya bahwa apabila umur responden meningkat sebesar satu tahun, implementasi KRPL meningkat sebesar 0,4 \%. Hal ini menunjukkan bahwa program KRPL bukan prioritas utama dalam penyediaan konsumsi pangan keluarga maupun sebagai tambahan penghasilan bagi keluarga. Terbukti dengan peningkatan hanya sebesar 0,4\% per tahun. Mereka cenderung membeli produk pangan keluarga dari pasar yang memang jaraknya cukup dekat.

3. Jenis kelamin $\left(\mathrm{X}_{2}\right)=-0,328$

Jenis kelamin anggota tidak mempengaruhi program KRPL dengan nilai koefisien sebesar - 0,328. Hal ini menunjukkan bahwa jenis kelamin anggota KRPL selama satu 
tahun, implementasi KRPL menurun sebesar 32,8 \%. Hal ini menunjukkan bahwa Setiap daerah memiliki kekhasan masing-masing dalam hal pengelolaan KRPL oleh masingmasing anggota. Daerah perkotaan cenderung dikelola oleh para ibu-ibu (wanita), sedangkan di Desa Awar-Awar peran anggota keluarga baik bapak, ibu dan anak lebih tampak, walaupun anggota KRPL tersebut adalah ibu.

4. Pendidikan $\left(\mathrm{X}_{3}\right)=0,160$

Pendidikan anggota mempengaruhi program KRPL dengan nilai koefisien sebesar 0,160. Hal ini menunjukkan apabila jenjang pendidikan responden meningkat sebesar satu tahun, implementasi KRPL meningkat sebesar $16 \%$. Hal ini menegaskan bahwa tingkat pendidikan formal merupakan faktor penting untuk mengetahui tingkat sumberdaya manusia. Makin tinggi tingkat pendidikan formal peserta program KRPL akan semakin rasional pola berfikirnya, dan daya nalarnya. Pendidikan merupakan sarana belajar untuk meningkatkan pengetahuan, yang selanjutnya akan menanamkan pengertian sikap dan mempengaruhi kemampuan peserta program KRPL untuk dapat bertindak yang lebih rasional sehingga semakin tinggi penerimaannya terhadap suatu inovasi.

5. Luas lahan $\left(\mathrm{X}_{4}\right)=0,007$

Luas lahan anggota tidak mempengaruhi program KRPL dengan nilai koefisien sebesar 0,007. Hal ini menunjukkan apabila luas lahan responden meningkat sebesar satu meter, implementasi KRPL meningkat sebesar 0,7 \%. Hal ini menunjukkan bahwa rata-rata luas perkarangan yang dimiliki peserta program KRPL relatif kecil dan ditanami dengan berbagai jenis tanaman. Dengan menanam berbagai macam tanaman dalam satu areal, konsekuensinya adalah produktivitas masing-masing tanaman tidak akan maksimal (kecil/sedikit).

6. Hobby $\left(\mathrm{X}_{5}\right)=1,204$

Hobby anggota mempengaruhi program KRPL dengan nilai koefisien sebesar 1,204. Hal ini menunjukkan apabila hobby/minat responden meningkat bertanam sayur, implementasi KRPL meningkat sebesar 120,4 \%. Hal ini menunjukkan bahwa faktor minat menjadi penentu keberhasilan program karena minat yang bisa diartikan sebagai kesenangan atau kecenderungan menjadikan anggota bersemangat dalam pengelolaan tanaman karena didasari kecintaan pada budidaya tanaman.

7. Pendampingan petugas $\left(\mathrm{X}_{6}\right)=0,135$

Pendampingan petugas tidak mempengaruhi program KRPL dengan nilai koefisien sebesar 0,135. Hal ini menunjukkan apabila pendampingan petugas meningkat sebanyak satu satuan, maka implementasi KRPL meningkat sebesar 13,5 \%. Hal ini menunjukkan bahwa pendampingan petugas sebagai fasilitator dan penyampai beragam inovasi budidaya kepada anggota KRPL tidak dijalankan secara optimalal sehingga anggota KRPL merasa dalam pengelolaan budidaya tanaman tidak mengerti apa yang harus dilakukan dan tidak mengerti untuk apa program ini dilaksanakan.

Untuk melihat pengaruh variable X secara keseluruhan / simultan terhadap implementasi program KRPL (Y) digunakan uji F. Dari hasil perhitungan statistik diatas, menunjukkan bahwa nilai $\mathrm{F}$ hitung sebesar 20,912 atau lebih besar dari $\mathrm{F}$ tabel yang hanya 2,85. Sehingga dapat dinyatakan bahwa model persamaan regresi diatas adalah benar.

\section{F hitung $>$ F tabel \\ $20.912>2.85$}

Dinyatakan benar, karena $\mathrm{F}$ hitung $>\mathrm{F}$ tabel, maka $\mathrm{H}_{0}$ ditolak dan $\mathrm{H}_{1}$ diterima. Dan dapat dikatakan bahwa secara simultan / keseluruhan / bersama-sama variabel variabel $\mathrm{X}_{1}$ sampai dengan $\mathrm{X}_{6}$ mempengaruhi implementasi program KRPL (Y), karena koefisien determinasi $\mathrm{R}^{2}=0,906$ maka variabelnya secara keseluruhan mempengaruhi 
implementasi program KRPL (Y) sebesar 90,6\%. Sedangkan sisanya sebesar 9,4\% dipengaruhi oleh faktor-faktor lain diluar variable yang telah ditetapkan oleh peneliti.

Selanjutnya untuk melihat pengaruh secara partial masing-masing variabel $\mathrm{X}_{1}$ sampai $\mathrm{X}_{6}$ terhadap faktor $\mathrm{Y}$ diuraikan sebagai berikut :

1. Variabel umur $\left(\mathrm{X}_{1}\right)$, mempunyai koefisien regresi sebesar 0,004 dengan taraf signifikansi sebesar 0,774 lebih besar dari 0,05, artinya bahwa variabel umur tidak mempunyai pengaruh positif dan tidak signifikan secara statistik terhadap impementasi program KRPL (Y). Hal ini terjadi karena, dalam melakukan program KRPL tidak melihat level usia tua atau muda anggota KRPL tetapi yang dilihat adalah seberapa besar ketrampilan ataupun minat anggota KRPL dalam membudidayakan tanaman sayuran di pekarangan.

2. Variabel Jenis kelamin $\left(\mathrm{X}_{2}\right)$, mempunyai koefisien regresi sebesar $-0,328$ dengan taraf signifikansi sebesar 0,235 lebih besar dari 0,05, artinya bahwa jenis kelamin tidak mempunyai pengaruh positif dan tidak signifikan secara statistik terhadap impementasi program KRPL (Y). Hal ini terjadi karena, budidaya tanaman sayuran di pekarangan merupakan usaha sampingan bahkan hobby, sehingga baik pria maupun wanita mampu untuk bercocok tanam di pekarangan.

3. Variabel pendidikan $\left(\mathrm{X}_{3}\right)$, mempunyai koefisien regresi sebesar 0,160 dengan taraf signifikansi sebesar 0,004 lebih kecil dari 0,05, artinya bahwa variabel pedidikan mempunyai pengaruh positif dan signifikan secara statistik terhadap impementasi program KRPL (Y). Hal ini terjadi karena, semakin tinggi level pendidikan seseorang maka akan semakin cepat dan mudah anggota KRPL dalam mengimplementasikan / transfer informasi teknologi dari petugas kepada anggota KRPL

4. Variabel luas lahan $\left(\mathrm{X}_{4}\right)$, mempunyai koefisien regresi sebesar 0,007 dengan taraf signifikansi sebesar 0,080 lebih besar dari 0,05, artinya bahwa variabel luas lahan tidak mempunyai pengaruh positif dan tidak signifikan secara statistik terhadap impementasi program KRPL (Y). Hal ini terjadi karena, hasil produksi tanaman sayur di pekarangan anggota bervariasi pada tingkat luas lahan dan mengalami fluktuasi harga pada saat anggota menjual sayuran hasil budidaya pekarangan, dan tergantung pada tingkat adopsi teknologi anggota KRPL itu sendiri.

5. Variabel hobby $\left(\mathrm{X}_{5}\right)$, mempunyai koefisien regresi sebesar 1,204 dengan taraf signifikansi sebesar 0,001 lebih kecil dari 0,05, artinya bahwa variabel hobby/ minat mempunyai pengaruh positif dan signifikan secara statistik terhadap impementasi program KRPL (Y). Hal ini terjadi karena, semakin besar minat seseorang dalam bercocok tanam di pekarangan maka akan semakin besar pula tingkat adopsi teknologi dari pendamping KRPL kepada anggota KRPL.

6. Variabel pendampingan petugas $\left(\mathrm{X}_{6}\right)$, mempunyai koefisien regresi sebesar 0,135 dengan taraf signifikansi sebesar 0,590 lebih besar dari 0,05, artinya bahwa variabel pendampingan petugas tidak mempunyai pengaruh positif dan tidak signifikan secara statistik terhadap impementasi program KRPL (Y). Hal ini terjadi karena, kurangnya pendampingan dari petugas terkait perihal transfer teknologi kepada anggota KRPL disamping itu pula kurangnya monitoring dari Dinas/instansi terkait

Peran variabel umur, jenis kelamin, luas lahan dan pendampingan PPL tidak berpengaruh nyata dibandingkan variabel pendidikan dan hobby/minat. Hal ini diduga bahwa keberlangsungan kegiatan KRPL, yang diintroduksikan pada tahun 2015, di lokasi tersebut lebih bergantung pada keaktifan masyarakat, maupun tokoh masyarakat yang dituangkan sebagai partisipasi secara aktif mendukung program KRPL, sementara umur, jenis kelamin, luas lahan dan pendampingan PPL masih belum dianggap sebagai faktor penentu kefektifan program ini khususnya dalam tahap awal program, yang artinya dengan teknologi yang sederhana pun kegiatan KRPL masih dapat berjalan dengan baik selama masyarakat berpartisipasi aktif. Namun, hal ini mengindikasikan pula agar dalam 
kelanjutan program KRPL di desa Awar-awar tersebut perlu memberikan ruang yang lebih banyak untuk memasukkan aspek teknologi khusunya dari peran pendamping PPL.

Dalam tahap implementasi, masyarakat sebagai peserta program biasanya akan mengalami rasa ketidak pastian ketika menerima suatu inovasi yang baru, yaitu merasa ragu dengan hasil yang akan diperoleh dari penerapan inovasi tersebut. Oleh karena itu, apabila diinginkan agar teknologi dapat diterima, masyarakat memerlukan pendampingan secara teknis baik oleh tokoh/personil yang dipercaya dan dianggap memiliki keahlian sehingga mampu mengurangi keraguan akan konsekuensi diterapkannya teknologi tersebut.di suatu kawasan akan mendukung lebih baiknya pelaksanaan kegiatan KRPL di tempat tersebut.

Demikian pula, dukungan dari Pemerintah Daerah setempat terhadap kegiatan KRPL akan memperluas implementasi kegiatan KRPL di daerah. Model ini juga menunjukkan bahwa tanpa adanya perlakuan dari variabel-variabel yang diuji, akan menyebabkan kegagalan program pada tahun-tahun mendatang.

\section{Efisiensi program KRPL}

Hasil analisa R/C rasio Efisiensi program Kawasan Rumah Pangan Lestari (KRPL) Desa Awar-Awar Kecamatan Asembagus disajikan pada tabel dibawahini

Tabel 3. Efisiensi Program KRPL Dasawisma Melati, Desa Awar-Awar Kecamatan Asembagus.

\begin{tabular}{cccc}
\hline & $\begin{array}{c}\text { Penerimaan } \\
(\mathrm{Rp})\end{array}$ & Biaya ( Rp ) & $\mathrm{R} / \mathrm{C}$ \\
\hline Anggota & 3.697 .000 & 4.271 .500 & 0,86 \\
\hline
\end{tabular}

Sumber : Data primer diolah

$\mathrm{R} / \mathrm{C}$ rasio dapat diketahui dari hasil pembagian antara total penerimaan dengan total biaya. Dari tabel di atas dapat dilihat bahwa nilai $\mathrm{R} / \mathrm{C}$ rasio Efisiensi program Kawasan Rumah Pangan Lestari (KRPL) memiliki nilai R/C ratio rata-rata sebesar 0,86 < , artinya bahwa program KRPL desa Awar-awar ini tidak efisien.

Secara keseluruhan, anggota yang memiliki minat bercocok tanam dan memiliki pekarangan yang luas $\left(>50 \mathrm{~m}^{2}\right)$ sehingga dalam mendapatkan hasil panen jelas lebih besar daripada anggota yang tidak memiliki cukup luas lahan pekarangan. Tetapi program ini tidak memberi efisiensi bagi sebagian besar anggota karena tidak memiliki pekarangan yang luas $\left(<50 \mathrm{~m}^{2}\right)$ dan hobby yang kurang diminati dalam bercocok tanam Sehingga dari data diatas dapat disimpulkan bahwa program KRPL di dasa desa Awar-Awar Kecamatan Asembagus tidak efisien.

\section{KESIMPULAN}

1. Efektivitas Program KRPL di desa Awar-Awar Kecamatan Asembagus sebesar $40 \%$ dan termasuk dalam kategori tidak efektif.

2. Berdasarkan uji $\mathrm{F}$, bahwa secara simultan/bersama-sama variabel variabel $\mathrm{X}$ mempengaruhi implementasi program KRPL (Y).

3. Berdasarkan uji $\mathrm{T}$, bahwa secara parsial hanya variabel pendidikan $\left(\mathrm{X}_{3}\right)$ dan hobby $\left(\mathrm{X}_{5}\right)$ yang mempengaruhi faktor implementasi KRPL (Y).

4. Program KRPL di dasa desa Awar-Awar Kecamatan Asembagus tidak efisien 


\section{REFERENSI}

Annisahaq, Amelia, dkk.2014. "Pengaruh Program Model Kawasan Rumah Pangan Lestari (Program M-KRPL) dalam mendukung Kemandirian Pangan dan Kesejahteraan Rumah Tangga (KASUS DI Kelurahan Rejomulyo, Kecamatan Kota, Kota Kediri)“. Jurnal Universitas Brawijaya. Malang.

Anonymous, 2005. Metodologi Penelitian Kuantitatif. Kencana. Jakarta.

Ashari. 2012. Potensi dan Prospek Pemanfaatan lahan pekarangan Untuk Mendukung Ketahanan Pangan. Jurnal Forum Penelitian Agro Ekonomi.Vol.30 Juli 2012. Jakarta.

Badan Ketahanan Pangan dan Pelaksana Penyuluhan Kabupaten Situbondo.2016. Petunjuk Pelaksanaan Kawasan Rumah Pangan Lestari. Situbondo.

Badan Ketahanaa Pangan Provinsi Jawa Timur. 2014. " Petunjuk Teknis Pengembangan Kawasan Rumah Pangan Lestari Plus Plus jawa Timur Tahun 2014 “. Surabaya.

Burhan. 2008. Metodologi Penelitian Kuantitatif. Kencana. Jakarta. Depdagri. 2012. Kepmendagri. No. 690.900.327. Tentang Pedoman Penilaian dan Kinerja Keuangan. Kementerian Dalam Negeri Republik Indonesia.

Enti Sirnawati, Astrina Yulianti, dan Amalia Ulpah, 2014. Faktor-Faktor Yang Mempengaruhi Keberhasilan Kawasan Rumah Pangan Lestari Di Pulau Sumatera. Jurnal Balai Besar Pengkajian dan Pengembangan Teknologi Pertanian. Jakarta.

Kementerian Pertanian. 2011. "Pedoman Umum Model KRPL Kementerian Pertanian 2011". (online). (http://id.scribd.com/doc/285932578/01- Laporan-Akhir-MKRPL-2011-pdf, diakses tanggal 29 Agustus 2019).

Sugiyono. 2012. Metode Penelitian Kuantitatif, Kualitatif, dan R \& D. Alfabeta. Bandung.

Softi Nur Rahmah, dkk. 2013. Optimalisasi Pemanfaatan Lahan Pekarangan Rumah Koto Baru Kecamatan Luhak Nan Duho Kabupaten Pasamaan Barat. STKIP PGRI. Sumatera Barat. 